\title{
Sheep have an unusual variant of the brain-specific metallothionein, metallothionein-III
}

\author{
Roger S. CHUNG*, Adele F. HOLLOWAY*, Bedrich L. ECKHARDT*, Julie A. HARRIS*, James C. VICKERS $†$, Meng Inn CHUAH $\ddagger$ \\ and Adrian K. WEST ${ }^{\star 1}$ \\ *Discipline of Biochemistry, University of Tasmania, Hobart, GPO Box 252-58, Tasmania, 7001Australia, †Discipline of Pathology, University of Tasmania, Hobart, \\ GP0 Box 252-58, Tasmania, 7001, Australia, and \$Discipline of Anatomy and Physiology, University of Tasmania, Hobart, GP0 Box 252-58, Tasmania, 7001, Australia
}

Sheep metallothionein-III (MT-III) cDNA was isolated from a brain cDNA library and characterized. In contrast with MT-III from other species, sheep MT-III cDNA is predicted to encode a protein with significantly different metal-binding properties, owing to the loss of three of its cysteine residues. RT-PCR from other sheep confirmed that this aberrant structure is ubiquitous in this species. MT-III was successfully isolated from sheep brain, demonstrating that the cDNA does give rise to a protein product of the predicted structure. Sheep MT-III is similar to other mammalian MT-IIIs in that it retains the Cys-Pro-Cys-Pro motif which is thought to encode growth-inhibitory activity, and we show that it is likewise able to inhibit neuron survival in vitro. This is the first naturally occurring variant of MT-III (or any other major mammalian MT gene) which gives rise to a protein product. These findings are discussed in light of proposed roles of MT in the mammalian brain.

Key words: gene expression, gene structure, growth-inhibitory factor.

\section{INTRODUCTION}

Metallothionein-III (MT-III) was discovered in 1991 during a search for growth-inhibitory factors which are down-regulated in the Alzheimer's-disease (AD) brain [1]. It has great similarity to other mammalian MT isoforms, for example, having 20 cysteine residues in conserved positions which confer binding of the heavy metals zinc and copper. Unlike the other MTs, it is predominantly expressed in the mammalian brain [2], although smaller levels have been observed in a few other tissues. It is probably expressed in both astrocytes [3] and a subset of neurons [4], and, unlike other MTs, its expression is not up-regulated by heavy metals.

The physiological role of MT-III is unclear. One intriguing possibility arises from its discovery as a growth-inhibitory factor [1], a property which is conferred by a specific amino acid motif Cys-Pro-Cys-Pro which is found in the N-terminal domain of the protein [5]. It has been observed that addition of human MT-III, but not other isoforms of MT, inhibits neurite sprouting and survival of rat cortical neurons in culture [1,5]. Interestingly, this effect is only seen in the presence of a brain homogenate, and it has been suggested that MT-III is deficient in AD brain $[1,6]$, although this notion has not been supported by other groups [7,8]. Other, more physiological, roles for MT-III include zinc metabolism in zincinergic neurons (particularly those of the CA3 field of the hippocampus) and response to neural damage and repair [9-11], but as in the case of other MT isoforms, no direct evidence for any of these roles has been obtained.

MT-III has been isolated from several mammalian species (human [1], horse and cow [12] and pig [13]), and its highly conserved structure suggests a tight evolutionary constraint. It is striking that, for all isoforms of mammalian MT, there has never been a major variant isolated, particularly with reference to the universally conserved cysteine residues. However, in the present study we demonstrate that MT-III from sheep has an unusual structure that lacks three conserved cysteine residues. Conversely, it does contain the Cys-Pro-Cys-Pro motif, and we show that it retains growth-inhibitory properties similar to those of human MT-III. Thus sheep contain a naturally occurring mutant of MT-III, suggesting that it might be possible to relate the role of MT-III to the neurological susceptibility of sheep to high levels of dietary heavy metals (and, in particular, copper).

\section{MATERIALS AND METHODS \\ Molecular analysis of sheep MT-III}

A cerebral cortex cDNA library was prepared using the ZAP express vector (Stratagene) and mRNA from adult merino ewes. About 60000 clones were screened with a radiolabelled probe derived by reverse-transcription PCR of mouse MT-III, using primer sequences published previously [2]. Hybridizing plaques were subjected to three rounds of purification and inserts characterized by DNA sequencing. For Southern- and Northernblotting experiments, a 147-bp HaeIII fragment of sheep MT-III cDNA was isolated and used as a radiolabelled hybridization probe in standard protocols [14]. When hybridized in a $50 \%$ formamide buffer at $42{ }^{\circ} \mathrm{C}$ and washed up to $0.2 \%$ SSC $(1 \times \mathrm{SSC}$ is $0.15 \mathrm{M} \mathrm{NaCl} / 0.015 \mathrm{M}$ sodium citrate $)$ at $37^{\circ} \mathrm{C}$, this probe revealed one band only and did not cross-react with other fragments containing sheep MT-I or MT-II genes.

\section{Protein isolation and analysis}

Isolation of crude brain homogenate

MTs from the brain and liver of adult female merino sheep were isolated using a protocol adapted from that described by Chen et al. [13]. Briefly, $20 \mathrm{~g}$ of freshly frozen sheep tissue was ground, homogenized and centrifuged. $\mathrm{CdCl}_{2}$ was added to the super-

Abbreviations used: AAS, atomic-absorption spectrophotometry; AD, Alzheimer's disease; MT, metallothionein; PBS-T, PBS/Tween-20; RT-PCR, reverse transcription PCR; DTT, dithiothreitol; EtBr, ethidium bromide.

1 To whom correspondence should be addressed (e-mail a.west@utas.edu.au). 
natant to a final concentration of $0.5 \mu \mathrm{g} / \mathrm{ml}$, and the mixture was heat-treated at $65^{\circ} \mathrm{C}$ for $10 \mathrm{~min}$. Denatured proteins were removed by centrifugation at $10000 \mathrm{~g}$, and MT proteins precipitated by addition of $6 \mathrm{vol}$. of ethanol, the material being kept overnight at $-20^{\circ} \mathrm{C}$.

Proteins were collected after centrifugation at $10000 \mathrm{~g}$, resuspended in $2-3 \mathrm{ml}$ of resuspension buffer and the supernatant cleared by centrifugation at $30000 \mathrm{~g}$.

\section{Gel-filtration chromatography}

Supernatants were applied to a Sephadex G-75 column $(31.5 \mathrm{~cm} \times 2.75 \mathrm{~cm}$; Pharmacia) equilibrated with elution buffer [20 mM Tris/HCl, pH 7.6, $1 \mathrm{mM}$ dithiothreitol (DTT) and $0.02 \% \mathrm{NaN}_{3}$ ]. Samples were eluted from the column at a flow rate of $1.2 \mathrm{ml} / \mathrm{min}$, and the $\mathrm{Cd}$ content of each fraction determined by atomic absorption spectrophotometry (AAS).

\section{Anion-exchange chromatography}

Appropriate fractions from the G-75 column were pooled and applied to a DEAE-cellulose column $(0.75 \mathrm{~cm} \times 7 \mathrm{~cm}$; Pharmacia) equilibrated with elution buffer $(20 \mathrm{mM}$ Tris $/ \mathrm{HCl}$, $\mathrm{pH} 7.6,1 \mathrm{mM}$ DTT and $0.02 \% \mathrm{NaN}_{3}$ ). Fractions were collected using a linear $100-300 \mathrm{mM} \mathrm{NaCl}$ gradient, at a flow rate of $0.4 \mathrm{ml} / \mathrm{min}$, and their Cd contents determined by AAS. Cdcontaining fractions were pooled and concentrated by ultrafiltration (molecular-mass cut-off $5 \mathrm{kDa}$ ).

\section{SDS/PAGE}

Samples were prepared for SDS/PAGE by adding $16.5 \mu 1$ of the sample to $7.5 \mu 1$ of $4 \times$ NuPage LDS sample buffer, vortexmixing, and addition of $6 \mu$ l of NuPage $10 \times$ Reducing Agent (all NuPage items were from Novex, San Diego, CA, U.S.A.). The sample was heated for $10 \mathrm{~min}$ at $70^{\circ} \mathrm{C}$ and electrophoresed on a ready-made $10 \%(\mathrm{w} / \mathrm{v})$ NuPage Bis-Tris gel in Mes buffer. Immediately after electrophoresis, the gel was incubated for $12 \mathrm{~h}$ at room temperature with gentle shaking in fixing solution, followed by two $30 \mathrm{~min}$ washes in $30 \%$ (v/v) ethanol. The gel was then washed three times in water, and subsequently incubated in 5 gel vol. of fresh $0.1 \% \mathrm{AgNO}_{3}$ for 30 min with gentle shaking.

Following this, both sides of the gel were washed under a stream of water, then incubated in fresh detection solution ( $2.5 \%$ sodium carbonate $/ 0.02 \%$ formaldehyde). Incubation was continued until the desired contrast was obtained.

\section{Western blotting}

Western blotting was performed using a method modified from that of Whitacre [15]. Briefly, the proteins were electrotransferred from the SDS/PAGE gel to a $0.45 \mu \mathrm{m}$ nitrocellulose membrane (Advantec MFC). After blocking with $5 \%(\mathrm{w} / \mathrm{v})$ skim milk in PBS-T (PBS/Tween-20) buffer, the filter was washed three times in PBS-T, followed by incubation overnight with primary antibody (anti-MT-I/-II; DAKO) at a dilution of 1:500 in PBS-T. The membrane was washed in PBS-T, and then incubated with secondary antibody [horseradish peroxidase-linked anti-(mouse Ig) antibody; Amersham] at a dilution of $1: 1000$ in PBS-T. Following three washes in PBS-T, the resultant immunofluoresence was detected using the Lumi-light Western Blotting Substrate Kit (Boehringer-Mannheim), and the membrane placed in a X-ray cassette and exposed to Hyperfilm ECL for various exposure times. The specificity of the anti-MT-I/-II antibody had been tested previously [14] and showed no cross-reaction with any other MT isoforms.

\section{Amino acid analysis}

Amino acid analysis was performed by the Nucleic Acid and Protein Chemistry Unit, University of Adelaide. Briefly, the sample was acidified with trifluoroacetic acid to generate apoMT, reduced with DTT and alkylated with iodoacetic acid. The sample was then hydrolysed to selectively cleave the $\mathrm{Asp}_{2}-\mathrm{Pro}_{3}$ site (to overcome $\mathrm{N}$-terminal blockage). Internal sequencing was performed by digesting the MT sample with subtilisin. Fragments were separated using a Pharmacia SMART system, followed by amino acid sequencing.

\section{Metal-binding analysis}

To determine the amount of sheep MT-III isolated, a sensitive (microgram quantities) protein-dye assay was used (Bradford protein assay [17]). Subsequently, the Cd content of known MT-III amounts was measured by AAS. From this, the molar equivalent of metal ions bound to MT-III was determined.

\section{Construction of recombinant expression vectors for human and sheep MT-III and human MT-IIA}

Recombinant human and sheep MT-III, and human MT-IIA, were prepared essentially as reported previously [5], using RTPCR subclones in the bacterial expression vector pET3d (Novagen). The structure of each construct was confirmed by DNA sequencing. Recombinant MTs were induced in the presence of $\mathrm{ZnSO}_{4}$ and were purified as described previously. Following anion-exchange chromatography, purified MT was then acidified with dilute $\mathrm{HCl}$ to $\mathrm{pH} 2.0$, and bound $\mathrm{Zn}^{2+}$ ions removed by applying the sample to an ultrafiltration column. The apo-MT was stored in aliquots at $-80^{\circ} \mathrm{C}$ until required. When required, the apo-MT was reconstituted with $\mathrm{Zn}^{2+}$ by the addition of 7.5 mol-equiv. (for human MT-III and MT-IIA), and 5.5 molequiv. (for sheep MT-III) of $\mathrm{Zn}^{2+}$, followed by neutralization of the sample to $\mathrm{pH} 8.0$ with $20 \mathrm{mM}$ Tris $/ \mathrm{HCl}$. The sample was desalted by ultrafiltration.

\section{Preparation of rat brain extract}

Rat brain extracts were prepared by homogenizing a freshly removed whole brain from a 4-week-old male Hooded Wistar rat (90-120 g) with a Potter-Elvehjem homogenizer in 5 vol. of icecold PBS, followed by centrifugation of the suspension at $30000 \mathrm{~g}, 4^{\circ} \mathrm{C}$. The supernatant was stored at $-80^{\circ} \mathrm{C}$. We found little difference between frozen and freshly prepared rat brain extract (results not shown). Following thawing, the brain extract was filter-sterilized $(0.22 \mu \mathrm{m}$ filter; Millipore), and the protein concentration determined by the Bradford method [17], and extracts were used immediately at a concentration of $150 \mu \mathrm{g} / \mathrm{ml}$.

\section{Neuron cultures}

Cortical tissue was removed from embryonic-day-18 Hooded Wistar rats and incubated in $4.5 \mathrm{ml}$ of sterile $10 \mathrm{mM}$ Hepes buffer $\left(37^{\circ} \mathrm{C}\right)$. A $0.5 \mathrm{ml}$ portion of $2.5 \%(\mathrm{w} / \mathrm{v})$ trypsin was added and the cells incubated at $37^{\circ} \mathrm{C}$ for $25 \mathrm{~min}$. To this, $0.5 \mathrm{ml}$ of trypsin inhibitor (40 BTEE units/mg of protein; 1 unit catalyses the hydrolysis of $1 \mathrm{~mol}$ of $N$-benzoyl-L-tyrosine ethyl ester/min at $25^{\circ} \mathrm{C}$ and $\mathrm{pH} 7.8$ ) was added for $5 \mathrm{~min}$ at $37^{\circ} \mathrm{C}$ and then $3 \mathrm{ml}$ of the Hepes buffer was gently removed, and replaced by $3 \mathrm{ml}$ of fresh Hepes buffer. This was repeated twice. A $2 \mathrm{ml}$ portion of the Hepes buffer was removed to increase cell density, and the remaining suspension triturated. The suspension was filtered through gauze (60 $\mu \mathrm{m}$ mesh size), and the number of cells 
counted by Trypan Blue exclusion. Cells were then plated on to glass coverslips $\left(132 \mathrm{~mm}^{2}\right)$ pre-coated with poly-L-lysine, at a cell density of 7500 cells/well.

After $3 \mathrm{~h}$, the medium was changed and fresh medium and $150 \mu \mathrm{g} / \mathrm{ml}$ rat brain extract added. The following day the medium was changed, and fresh medium and brain extract added, as well as a range $(0.2 \mu \mathrm{g} / \mathrm{ml}, 1 \mu \mathrm{g} / \mathrm{ml}$ or $5 \mu \mathrm{g} / \mathrm{ml})$ of recombinant MT concentrations where appropriate. Cultures were maintained at $37{ }^{\circ} \mathrm{C}$ in humidified air containing $5 \% \mathrm{CO}_{2}$ for 3 days, at which time they were fixed with $4 \%$ paraformaldehyde, and stained with an anti-(microtubule-associated protein-2) primary antibody (DAKO), followed by streptavidin-conjugated goat anti-mouse IgG secondary antibody application (DAKO LSAB Kit 2) and visualization using diaminobenzidine. Previous experiments showed that there was virtually no contamination of these neuron cultures with other cell types (results not shown). For analysis of neuron survival, two digital images per quadrant (one towards the centre and one towards the outside) were taken from each coverslip, at a magnification of $40 \times$ (Olympus BL-51 microscope). The number of cells counted per coverslip ranged from 50 to 120 cells.

\section{RESULTS}

\section{Structure of sheep MT-III cDNA}

A cDNA library was constructed from sheep brain mRNA in the ZAP express bacteriophage vector and was screened using a PCR fragment derived from mouse MT-III cDNA. A total of 12 clones were purified and analysed by sequencing, and two were found to be full-length cDNA clones. As shown in Figure 1, the protein predicted by these clones is a 65-amino-acid MTlike protein containing 17 cysteine residues. The protein appears to contain a single amino acid 'insertion' in the $\mathrm{N}$ terminal domain and a six-amino-acid-residue insertion in the C-terminal domain, thus identifying this clone as an MT-III. The predicted protein is clearly homologous to previously identified MT-III proteins, with 87 and $85 \%$ homology to bovine and equine proteins respectively (results not shown; [12]). It also contains the motif Cys-Pro-Cys-Pro, which is thought to confer the growth-inhibitory functions of this protein [5].
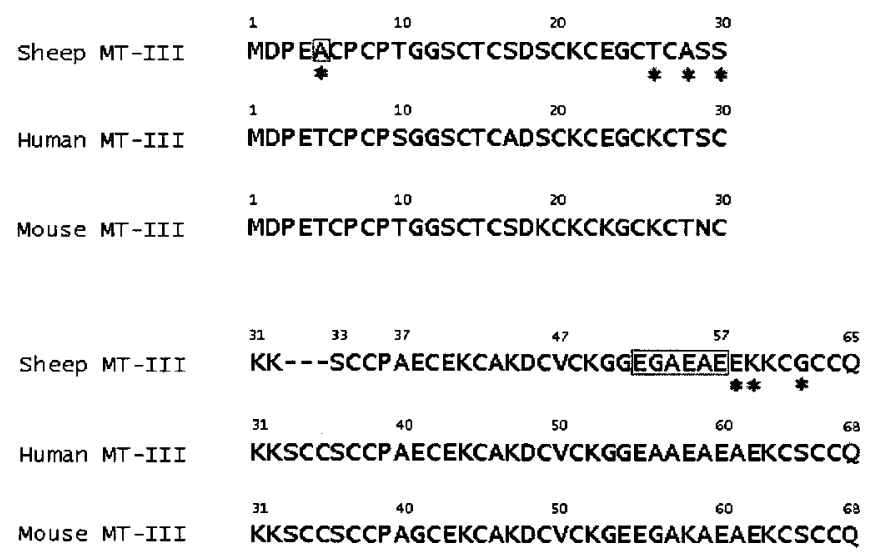

Figure 1 Comparison of the predicted protein sequence (from cDNA) of sheep MT-III with human and mouse MT-III proteins

Comparison of the predicted protein sequence of sheep MT-III with human MT-III and mouse MT-III, showing the three-amino-acid deletion (Ser-Cys-Cys) in sheep MT-III, normally conserved at positions 33-35 of MT-III proteins. Amino acids found in the sheep MT-III protein but not in human or mouse MT-III are indicated by asterisks.
There are, however, some significant differences between the predicted sheep MT-III protein and other mammalian MT-IIIs. Most obviously, sheep MT-III appears to contain three fewer cysteine residues, owing to the apparent deletion of the sequence Ser-Cys-Cys (normally found at positions 33-35 of MT-III proteins) and the replacement of a cysteine residue normally found at position 30 with serine. The number and location of cysteine residues is a hallmark of mammalian MTs, including MT-III, and are conserved throughout the vast majority of members of the family.

The cDNAs described above were all derived from an individual sheep, so to confirm that the unusual MT-III structure was found in other sheep, PCR primers were designed which flank the MT-III cDNA coding region. These were used in RTPCR with RNA from a further five individual merino sheep, and this analysis confirmed the structure of sheep MT-III as shown in Figure 1, with the exception of a single polymorphism whereby the cysteine residue at position 22 was encoded by either TGT or TGC. We also found that cDNA from Pol Dorset sheep encoded a similar MT-III protein (results not shown). Another explanation for the unusual structure of this cDNA is that it has been derived from a mutated version of the MT-III gene, and that a second gene exists in the sheep genome with a structure more consistent with mammalian MT-III genes. This would appear to be unlikely, since all cDNA clones (a total of 12 were characterized) and RT-PCR products were consistent; however, as a further check a Southern blot using DNA from two further animals was carried out using either a fragment of the sheep MTIII cDNA, or a fragment of the mouse MT-III as a probe. Neither of these probes hybridized to previously characterised sheep MT-I or MT-II genes. This analysis revealed only a single EcoR1 fragment of $4.4 \mathrm{~kb}$ (results not shown), strongly suggesting that only one MT-III gene is present in the sheep genome.

\section{Expression of sheep MT-III}

Northern blotting was used to determine the expression characteristics of sheep MT-III. Using a HaeIII fragment of the MT-III cDNA clone as a probe, Figure 2, upper panel, shows that MTIII is expressed predominantly in the adult sheep brain and late fetal brain (E116), but is not detectable in the early developmental stages, nor in liver, kidney, lung, heart or gut. As shown in Figure 2, lower panel, MT-III mRNA is present in most anatomical regions of the adult sheep brain and is highly expressed in the pineal gland and the midbrain. As has been noted previously, the relative levels of MT-III and MT-I/-II mRNA are similar from region to region in the brain [18], despite the apparently different physiological roles ascribed to these proteins. Hence like other mammalian MT-III genes, that for sheep MT-III appears to be expressed predominately in the postnatal brain.

\section{Isolation of MT-III protein}

To verify that sheep MT-III is fully expressed, MT-III protein was isolated from sheep brain homogenate by gel filtration and ion-exchange chromatography. The crude brain homogenate was firstly spiked with Cd to enable the Cd-thionein to be easily detected by AAS, and was then subjected to heat and solvent treatment. The resultant crude extract was applied to a Sephadex G-75 column and the resultant large peak at around $6 \mathrm{kDa}$ (the predicted size of MTs, including MT-III) then applied to a DEAE-cellulose column. Fractions were eluted with a linear 100-350 mM NaCl gradient, and several distinct Cd-containing 

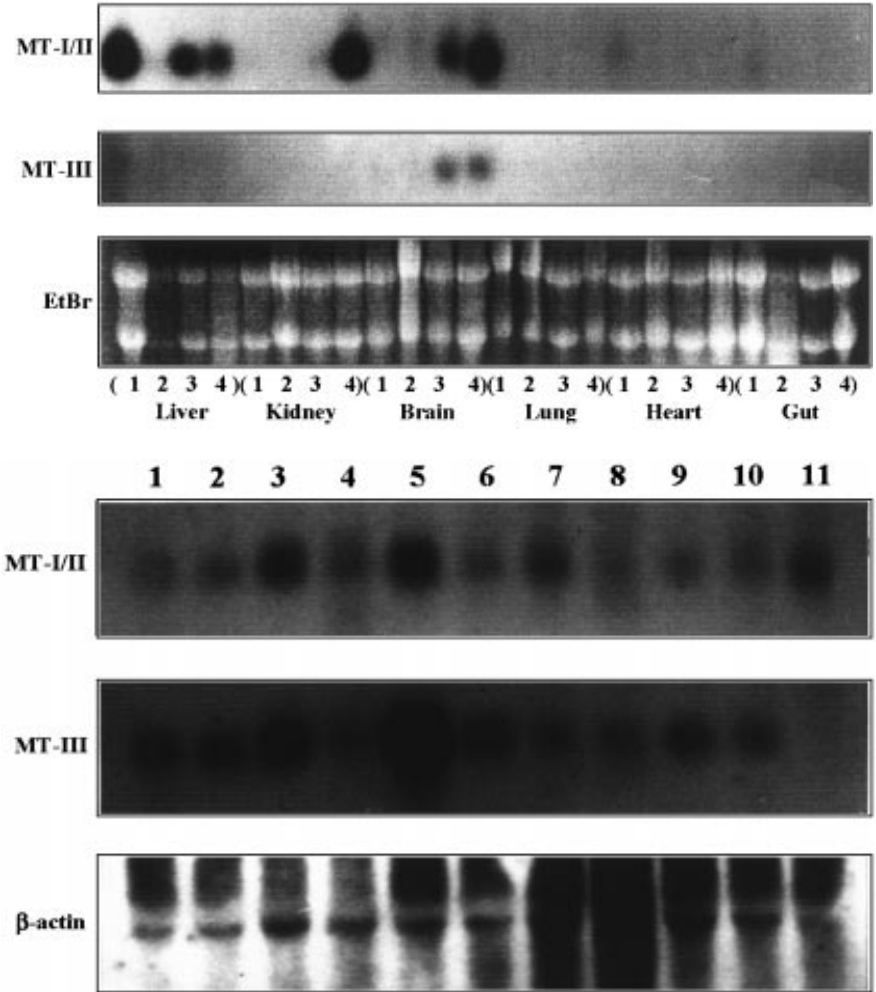

Figure 2 Sheep MT-III mRNA is expressed in post-natal brain (upper panel) and is present in most regions of the sheep brain (lower panel)

Upper panel: Northern blot of sheep RNA obtained from the tissues as indicated. The sheep were of the following developmental ages: 1, E72 (embryonic day 72); 2, E80; 3, E116; 4, adult. The blots were probed with a sheep MT-III cDNA probe (MT-III) or a human MT-IIA cDNA probe (MT-I/II) which hybridizes to all known sheep MT-1 and MT-II genes. Staining with ethidium bromide (EtBr) was used to indicate the relative amount of RNA in each track. Lower panel: Northern blots were done using RNA from the following regions of the adult sheep brain: 1 , frontal cortex; 2, occipital cortex; 3 , midbrain; 4, brain stem; 5 , pineal gland; 6, basal ganglia; 7, hypothalamus; 8 , thalamus; 9 , hippocampus; 10 , choroid plexus; 11 , liver. The probes used were the same as in (A), except that hybridization to a $\beta$-actin probe was used to indicate levels of RNA in each track.

fractions were collected. A parallel purification of sheep liver homogenate was also run which, on the basis of mRNA expression profiles, would be expected to contain MT-I/-II but not MT-III. As can be seen in Figure 3, this produced a similar profile to cortex, except that a peak eluted at approx. $250 \mathrm{mM}$ $\mathrm{NaCl}$ (peak 2) was not present.

Each of the Cd-containing peaks was collected and, after ultrafiltration with a $5 \mathrm{kDa}$ cut-off filter, was subjected to SDS/PAGE (Figure 4). A duplicate gel was Western-blotted using E9, a monoclonal antibody that we have shown to be specific for MT-I/-II but not MT-III [14]. It is evident that immunoreactive MT-I/-II has been isolated from both sheep cortex (lane 1) and liver (lane 2) and runs at the predicted molecular mass $(6 \mathrm{kDa})$. As seen elsewhere, MTs tend to polymerize when not carboxymethylated and hence produce a ladder of bands. These samples eluted from the DEAE-cellulose column at the same position as rabbit MT-I/-II (peak 1; results not shown). However peak 2, which was only present in sheep cortex, gave rise to a single band of about $6 \mathrm{kDa}$ that did not cross-react with the anti-MT-I/-II antisera, and hence is sheep MT-III.

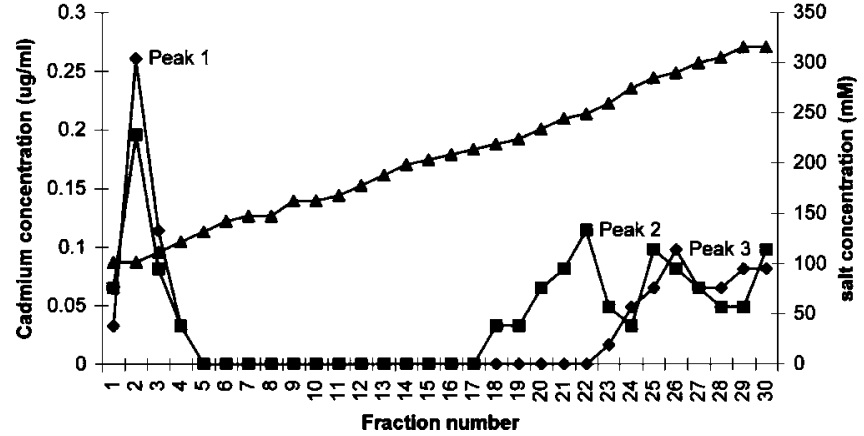

Figure 3 Anion-exchange chromatography of sheep cortex and liver preparations

Sheep cortex ( $)$ and liver $(\bullet)$ preparations were eluted from the column by a linear $\mathrm{NaCl}$ gradient $(\boldsymbol{\Lambda})$. Fractions were analysed for their $\mathrm{Cd}$ content by AAS, and $\mathrm{Cd}$-containing peaks (peaks 1, 2 and 3) were collected for analysis by SDS/PAGE and Western blotting.

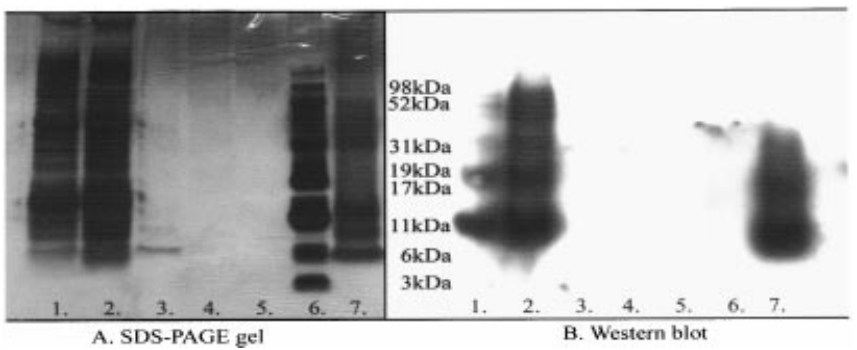

Figure 4 SDS/PAGE and Western-blotting analysis

Ultrafiltrated Cd-containing peaks from anion-exchange chromatography were analysed by SDS/PAGE (A). Lanes are: 1, peak 1, sheep cortex; 2, peak 1, sheep liver; 3, peak 2, sheep cortex; 4, peak 3, sheep cortex; 5, peak 3, sheep liver; 6, markers; 7, rabbit MT-I/-II (Sigma). A duplicate SDS/PAGE gel was Western-blotted with a MT-I/-II primary antibody (B).

\section{Protein and amino acid sequence analysis}

Sheep MT-III isolated from the cortex (as above) was subjected to partial amino acid sequence analysis, both from the $\mathrm{N}$ terminal end (after unblocking) and from an internal subtilisin site. Obtained sequences unambiguously identified the isolated protein as sheep MT-III, with a structure identical with that predicted from the cDNA sequence. In conjunction with this protein's immunological and molecular-mass profile, as assessed by Western blotting, and with its characteristic behaviour on anion-exchange chromatography, these data clearly confirm that the unusual sheep MT-III is indeed expressed at the protein level in sheep brain.

To investigate the predicted alteration in metal-binding properties of sheep MT-III, Cd-MT-III isolated from sheep cortex was analysed by AAS. This analysis indicated that sheep Cd-MT-III binds five $\mathrm{Cd}$ ions per molecule, confirming that the predicted structure of sheep MT-III has a metal-binding stoichiometry different from that of other mammalian MTs.

\section{Cell-culture studies}

Recombinant sheep MT-III, human MT-III and human MT-IIA were produced by subcloning RT-PCR products into the bacterial expression vector pET3d, essentially as described by Sewell et al. [5]. Recombinant proteins were examined for their ability to 


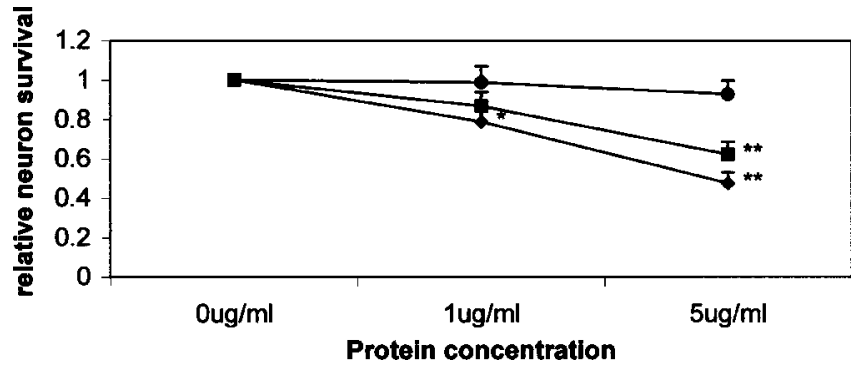

Figure 5 Neuron survival in the presence of recombinant sheep MT-III

Rat cortical neurons were cultured with either human $(\bullet)$, sheep ( $\boldsymbol{\square})$ MT-III, or human MT-IIA (O), all in the presence of rat brain extract $(150 \mu \mathrm{g} / \mathrm{ml})$. Relative neuron survival was determined by dividing the number of neurons per field of view in the presence of added recombinant MT by the number of neurons per field of view in the absence of added recombinant MT. ${ }^{*} P<0.05 ;{ }^{* *} P<0.001$ (significance values determined using a Student's $t$ test) ( $n=12$ for controls, $n=6$ for MT treatments)

inhibit neuron survival after 3 days using cultured rat cortical neurons. As shown in Figure 5, 1 and $5 \mu \mathrm{g} / \mathrm{ml}$ of human MT-III decreased neuronal survival by 22 and $53 \%$ respectively, similar to that reported previously $[5,7]$. A control recombinant protein, human MT-IIA, did not reduce neuronal survival, as expected. This is in accordance with observations made with other MTI/-II isoforms (recombinant rat MT-I/II [5]; recombinant mouse MT-I [7]). However, recombinant sheep MT-III also reduced neuron survival by 13 and $37 \%$ when added to the cultures at 1 and $5 \mu \mathrm{g} / \mathrm{ml}$ respectively.

\section{DISCUSSION}

Like other mammalian MTs, no conclusive physiological role in the brain has been ascribed to MT-III, despite these proteins being widespread in most neural structures [19]. Initial reports suggested that MT-III might, on the basis of its ability to inhibit neuron survival in cell culture models, have a growth-inhibitory function. Alternatively MT-III's metal-binding properties, and localization, in part, in zincinergic neurons, also suggests roles in metal homoeostasis. Further, recent evidence shows that MT-III, like the other members of its family, have a general protective effect following various types of neural injury [10,11], although the mechanism for this remains undefined.

A most exciting potential role for MT-III was suggested by its apparent deficiency in AD brain, the notion being that this deficiency was a causative factor in the development of neurofibrillary tangles [1], a hallmark of AD. Conflicting results have been reported, however, suggesting that there is no deficiency in MT-III in the AD brain [7]. A recent report has again indicated a deficiency of MT-III in the AD brain, further clouding the issue [6]. The finding that MT-III can inhibit the formation of neurotoxic $\beta$-amyloid aggregations in vitro [20] has also suggested that MT-III may be involved in the development of AD.

Most of these proposed properties of MT-III are dependent on the unusual structure of this protein and, in particular, the presence of 20 conserved cysteine residues which are essential for MT's metal-binding and redox characteristics. No significant variation in the number or relative position of these cysteine residues has been observed in previously isolated mammalian MTs [21]. Furthermore, MT-III's putative neurotrophic properties have been ascribed to the presence of a motif (Cys-Pro-CysPro) present in the neural-predominant MT-III isoform, but not in other MTs.
Here we show that sheep express, at the protein level, an MTIII with unique structural features compared with previously characterized MT-III proteins which may therefore be useful in determining the physiological role of MT-III isoforms and their relationship to other MTs. The most striking feature of the sheep MT-III protein in comparison with any other mammalian MT is a deletion of three amino acids (Ser-Cys-Cys) at positions 33-35. This Ser-Cys-Cys sequence occurs directly after the two lysine residues forming the bridge between the $\alpha$ - and $\beta$-domains of the MT protein. This sequence also forms the start of the $\alpha$-domain of the protein and is conserved among all mammalian MT protein sequences documented thus far [22]. Deletion of these amino acids is likely to affect the structure of the protein and is unlikely to be an artifact, since it was observed in seven individual sheep of two different strains. There are three conserved cysteine residues missing from the sheep MT-III protein - those normally found at positions 34 and 35, which are deleted, and the cysteine residue usually conserved at position 30 , which is a serine residue in sheep MT-III.

The metal-binding stoichiometries of MT-I and -II isoforms for $\mathrm{Zn}, \mathrm{Cd}$ and $\mathrm{Cu}$ are well documented and appear to be identical for all mammalian MTs, including human and mouse MT-III proteins [22]. These consist of two separate domains, binding a total of 7 mol-equiv. of the bivalent metals $\mathrm{Cd}$ and $\mathrm{Zn}$, or 12 copper ions. The sheep MT-III protein is missing one terminal cysteine residue from the $\beta$-domain and two cysteine residues (one bridging, one terminal) from the $\alpha$-domain which are normally involved in the binding of three of the seven bivalent metal ions in the MT-metal clusters. Indeed, analysis indicated that sheep MT-III binds only five Cd ions per molecule. This alteration in metal-binding properties is not surprising, as others have found Chinese-hamster MT mutants C13Y, C50Y and $\mathrm{C} 13 \mathrm{Y} / \mathrm{C} 50 \mathrm{Y}$ (in which Cys13, Cys50, or both Cys13 and Cys50, are mutated to tyrosine residues) had metal-binding domains which tended to be folded less tightly and all three mutants bound 6 rather than 7 mol-equiv. of $\mathrm{Cd}$ [23]. While some mutants retained their ability to protect against Cd toxicity, others had reduced detoxification function $[23,24]$.

Interestingly, it has been well documented that naturally sheep are particularly prone to both deficiency (swayback disease) $[25,26]$ and overloading with dietary copper (chronic copper toxicity) [27]. Both conditions, while initially affecting the liver and kidney, ultimately lead to dramatic neurological deficiencies, ranging from numerous lesions in the white matter (swayback [28]) to severe swelling and vacuolation of the white matter and swelling of astrocytes (chronic copper toxicity [27,29]). The underlying biochemical mechanisms which lead to the neurological progress of these diseases are unknown, but it has been suggested that these diseases may be caused by the neurological miss-handling of copper in the brain. It is conceivable that sheep MT-III may be intimately involved in the susceptibility of sheep to copper, either by reducing copper storage/handling or due to an alteration in the physiological function of sheep MT-III (such as reduced free-radical-scavenging ability). It must be noted that MT-III knockout mice have been found to exhibit no apparent phenotypic changes up to 2 years of age [9]. However, sheep are much longer lived than rats, and frequently exposed to environmental fluctuations in heavy metals such as copper. Thus it may be that sheep provide a model for revealing important physiological information on the role of MT-III.

Interestingly, sheep MT-III retains the motif Cys-Pro-Cys-Pro and, as is the case for human and mouse MT-III, the sheep isoform also possesses growth-inhibitory properties. It is unlikely that MT-III acts in this way in vivo, since MT-III is thought to be predominantly intracellular, whilst the in-vitro-cultured- 
neuron assay uses exogenous extracellular protein. However, the fact that this motif is retained in all MT-III members characterized so far, including this unusual variant, is highly suggestive that it is relevant to the role of MT-III, and one possibility is that MT-III released from lysed astrocytes in the aftermath of physical injury modifies the subsequent neuronal response. For example, Erickson et al. [7] calculated that human frontal cortex contains around $20 \mu \mathrm{g} / \mathrm{g}$ MT-III in the brain, and given that necrosis or physical damage could cause extensive lysis of cells, it is possible that extracellular concentrations of MT-III could reach the levels that we and others have shown to have significant effects on neuron survival and neurite sprouting (i.e. in the vicinity of $1-5 \mu \mathrm{g} / \mathrm{ml})$. This would accord with other evidence that MTs in the brain are involved in the response of this organ to chemical and physical stress.

This work was funded by the Motor Accident and Insurance Board (MAIB) of Tasmania. We also thank Jon Howe for his contribution during the early part of this project.

\section{REFERENCES}

1 Uchida, Y., Takio, K., Titani, K., Ihara, Y. and Tomonaga, M. (1991) The growth inhibitory factor that is deficient in the Alzheimer's disease brain is a 68 amino acid metallothionein-like protein. Neuron 7, 337-347

2 Palmiter, R. D., Findley, S. D., Whitmore, T. E. and Durnam, D. M. (1992) MT-III, a brain-specific member of the metallothionein gene family. Proc. Natl. Acad. Sci. U.S.A. 89, 6333-6337

3 Yamada, M., Hayashi, S., Hozumi, I., Inuzuka, T., Tsuji, S. and Takahashi, H. (1996) Subcellular localization of growth inhibitory factor in rat brain: light and electron microscopic immunohistochemical studies. Brain Res. 735, 257-264

4 Masters, B. A., Quaife, C. J., Erickson, J. C., Kelly, E. J., Froelick, G. J., Zambrowicz, B. P., Brinster, R. L. and Palmiter, R. D. (1994) Metallothionein-III is expressed in neurons that sequester zinc in synaptic vesicles. J. Neurosci. 14, 5844-5857

5 Sewell, A. K., Erickson, J. C., Palmiter, R. D. and Winge, D. R. (1995) Bioactivity of metallothionein-3 correlates with its novel $\beta$ domain sequence rather than metal binding properties. Biochemistry 34, 4740-4747

6 Yu, W. H., Lukiw, W. J., Bergeron, C., Niznik, H. B. and Fraser, P. E. (2001) Metallothionein III is reduced in Alzheimer's disease. Brain Res. 894, 37-45

7 Erickson, J. C., Sewell, A. K., Jensen, L. T., Winge, D. R. and Palmiter, R. D. (1994) Enhanced neurotrophic activity in Alzheimer's disease cortex is not associated with down-regulation of metallothionein-III. Brain Res. 649, 297-304

8 Carrasco, J., Giralt, M., Molinero, A., Penkowa, M., Moos, T. and Hidalgo, J. (1999) Metallothionein (MT)-III: generation of polyclonal antibodies, comparison with MT-I+ II in the freeze lesioned rat brain and in a bioassay with astrocytes, and analysis of Alzheimer's disease brains. J. Neurotrauma. 16, 1115-1129

9 Erickson, J. C., Hollopeter, G., Thomas, S. A., Froelick, G. J. and Palmiter, R. D. (1997) Disruption of the metallothionein-III gene in mice: analysis of brain zinc, behaviour, and neuron viability to metals, aging, and seizures. J. Neurosci. 17, $1271-1281$

Received 30 November 2001/6 March 2002; accepted 2 April 2002

Published as BJ Immediate Publication 2 April 2002, D0I 10.1042/BJ20011751
10 Carrasco, J., Hernandez, J., González, B., Campbell, I. L. and Hidalgo, J. (1998) Localisation of metallothionein-I and -III expression in the CNS of transgenic mice with astrocyte-targeted expression of interleukin 6. Exp. Neurol. 153, 184-194

11 Acarin, L., Carrasco, J., Gonzalez, B., Hidalgo, J. and Castellano, B. (1999) Expression of growth inhibitory factor (metallothionein-III) mRNA and protein following excitotoxic immature brain injury. J. Neuropathol. Exp. Neurol. 58, 389-97

12 Poutney, D. L., Fundel, S. M., Faller, P., Birchler, N. E., Hunziker, P. and Vasak, M. (1994) Isolation, primary structures and metal binding properties of neuronal growth inhibitory factor (GIF) from bovine and equine brain. FEBS Lett. 345, 193-197

13 Chen, C. F., Wang, S. H. and Lin, L. Y. (1996) Identification and characterisation of metallothionein-III (growth inhibitory factor) from porcine brain. Comp. Biochem. Physiol. B Biochem. Mol. Biol. 115, 27-32

14 Maniatis, T., Fritsch, E. F. and Sambrook, J. (1982) Molecular Cloning: a Laboratory Manual, Cold Spring Harbor Laboratory Press, Cold Spring Harbor, NY

15 Whitacre, C. M. (1996) Application of western blotting to the identification of metallothionein binding proteins. Anal. Biochem. 234, 99-102

16 Skabo, S. J., Holloway, A. F., West, A. K. and Chuah, M. I. (1997) Metallothioneins 1 and 2 are expressed in the olfactory mucosa of mice in untreated animals and during the regeneration of the epithelial layer. Biochem. Biophys. Res. Commun. 232 , 136-142

17 Bradford, M. M. (1976) A rapid and sensitive methods for the quantitation of microgram quantities of protein utilizing the principle of protein-dye binding. Anal. Biochem. 72, 248-254

18 West, A. K., Holloway, A. F., Stennard, F. A. and Miller, J. M. (1999) Metallothionein expression in the mammalian brain. In Metallothionein IV (Klaasen, C., ed.), Birkhauser Verlag, Basel

19 Miles, A. T., Hawksworth, G. M., Beattie, J. H. and Rodilla, V. (2000) Induction, regulation, degradation, and biological significance of mammalian metallothioneins Crit. Rev. Biochem. Mol. Biol. 35, 35-70

20 Irie, Y. and Keung, W. M. (2001) Metallothionein-III antagonizes the neurotoxic and neurotrophic effects of amyloid beta peptides. Biochem. Biophys. Res. Commun. 282 , 416-420

21 Kagi, J. H. R. (1993) Evolution, structure and chemical activity of class I metallothioneins (an overview). In Metallothionein III: Biological Roles and Medical Implications (Suzuki, K. T., Imura, N. and Kimura, M., eds.), pp. 29-56, Birkhauser Verlag, Basel

22 Bogumil, R., Faller, P., Poutney, D. L. and Vasak, M. (1996) Evidence for Cu(I) clusters and $\mathrm{Zn}(\mathrm{II})$ clusters in neuronal growth-inhibitory factor isolated from bovine brain. Eur. J. Biochem. 238, 698-705

23 Cismowski, M. J. and Huang, P. C. (1991) Effect of cysteine replacements at positions 13 and 50 on metallothionein structure. Biochemistry 30,6626-6632

24 Chernaik, M. L. and Huang, P. C. (1991) Differential effect of cysteine-to-serine substitutions in metallothionein on cadmium resistance. Proc. Natl. Acad. Sci. U.S.A 88, 3024-3028

25 Howell, J., Davison, A. N. and Oxberry, J. (1964) Biochemical and neuropathological changes in swayback. Res. Vet. Sci. J. 5, 376-384

26 Alleyne, T., Joseph, J., Lalla, A., Sampson, V. and Adogwa, A. (1998) Cytochrome-c oxidase isolated from the brain of swayback-diseased sheep displays unusual structure and uncharacteristic kinetics. Mol. Chem. Neuropathol. 34, 233-247

27 Doherty, P. C., Barlow, R. M. and Angus, K. W. (1969) Spongy changes in the brains of sheep poisoned by excess dietary copper. Res. Vet. Sci. 10, 303-305

28 Tan, N. and Urich, H. (1983) Menke's disease and swayback: a comparative study of two copper deficiency syndromes. J. Neurol. Sci. 62, 95-113

29 Morgan, K. T. (1973) Chronic copper toxicity of sheep: an ultrastructural study of spongiform leucoencephalopathy. Res. Vet. Sci. 15, 89-95 